\title{
Organisational Climate for Change And Innovativeness: A Social Capital Perspective
}

HELEN BLACK, ANNEKE FITZGERALD

Helen Black, Western Sydney University, School of Business, Penrith, New South Wales 2751, Australia Anneke Fitzgerald, Griffith University - IBA, Gold Coast Campus Parklands Dr, Southport, Queensland 4215, Australia

Correspondence: h.black@westernsydney.edu.au

\begin{abstract}
Purpose: Acute health services around the world are increasingly required to respond to accreditation institutes, the changing needs and expectations of patients and societal values that demand continuous improvement in quality and efficiencies. Many change initiatives and innovative attempts have failed or resulted in lower performance than expected. The purpose of this paper is to increase understanding of the organisational contextual factors such as social capital and organisational climate that interact with the change implementation processes and provide a new perspective for change management in the unique environment of acute health care.
\end{abstract}

Methodology: This mixed methods study was executed in three different sized operating theatre suites. A survey and in-depth interviews were used to reveal a current organisational climate for innovativeness through team member perspectives. The strength of each organisational climate was assessed with reference to the level of disparity in the participant responses. In-depth interviews and observations provided understanding of how social capital is developed and maintained, then examined in context with the climate for innovativeness to understand how contextual factors, social capital and climate interact.
Findings: It has been demonstrated that social capital in the operating theatre suite has bearing on the organisational climate for change and innovativeness. Size and structure of an organisation influence how social networks develop; policies and management practices influence how different networks interact; and, the combination of contextual factors and social capital influences the organisational climate for innovativeness.

Originality/value: Managing social capital can offer a people-focused perspective through which to design and implement change and enhance an organisational climate for innovativeness.

Keywords: social capital, organisational climate, change initiatives, redesigning healthcare organisations 
Health services in Australia and elsewhere are under constant pressure to increase throughput and improve efficiencies, including in surgical departments. [1] However, acute health services are characterised by highly specialised activities, unique organisational and social structures, and seemingly endless demand for better, faster and more efficient performance. [1-5] These pressures contribute to a continual need for change and innovativeness to achieve organisational efficiency and effectiveness. In a highly specialised environment, such as an operating suite where individual professional autonomy is of great importance, [6-8] increasing pressure from centralised reform initiatives creates a sense of ambiguity. [1-3,5,9] Thus, the combination of highly specialised activities and complex organisational and social structures provides an interesting context to explore social capital and organisational climate for innovativeness, especially when implementing change initiatives.

Designing and implementing change initiatives in any organisation can be challenging. [10-12] The operating theatre suite context is a unique and high risk environment [13] making implementation of change initiatives particularly complex. [14] For instance, in Australia a large amount of doctors are Visiting Medical Officers (VMO's). VMOs, such as surgeons, are not employed by the organisation and as such they interact differently in a formal organisational hierarchy creating a level of complexity to any change initiative.

In many cases, change initiatives have not delivered the expected level of improvements due to the focus of short term outcomes and technical implementation systems rather than developing an in-depth understanding of contextual and social factors to enhance the change and innovative processes. [15-24] Hence, it is essential to consider what people bring to the organisation in terms of social capital. Therefore, social capital is an important factor in managing the climate for change and innovativeness of an operating theatre suite. [25]

In this study, a climate for change and innovativeness encompasses factors including aspects of openness to doing things differently, accepting/embracing ideas from outside, acceptance of risk taking, fostering team spirit, considering the effects of internal politics, levels of staff motivation, and levels of commitment to organisational goals. [25] Whether change initiatives are introduced from outside or innovativeness is initiated from within organisational units, this research proposes that one way of leading and maintaining a climate for change and innovativeness is for managers to direct their attention to managing social capital.

\section{Literature Review}

Social capital is a dynamic concept that has been described in the literature through tie strength, $[26,27]$ extent of network closure, [28-32] and brokerage between networks. [33]

Social capital is referred to in the management literature as both an individual and a collective asset. [26, 34-40] Individual benefits to organisational members include the human need for membership and identification, satisfaction gained from the recognition of peers, and the inherent gratification of both giving and receiving support. [35] Organisational and collective benefits include 
the quality of networks and relationships that enable individuals to cooperate and collaborate for collective purposes $[26,36,38]$ and achievement of organisational goals through goal congruence. This paper aims to make the relationship between social capital and organisational climate explicit.

Social capital as a collective asset, refers to the quality of networks and relationships that enables individuals to cooperate and collaborate for collective purposes. [26,36,38] A sense of belonging and collective identity enhances trust and creates more effective collaboration in all environments, including operating theatre suites. Hence trust, a characteristic of social capital, is important in a climate for change and innovativeness.

Literature about social relationships in organisations indicates that the structure and quality of team member relationships may mediate the climate for change and innovativeness. [41-44] Social relationships provide a valuable organisational resource as an internal social structure, and may enhance the climate for change and innovativeness. [25] In organisational settings that are characterised by interdependence, such as acute health services, the quality of social relationships takes on greater importance. [41]

Cohen and Prusak [35] argue that things happen, or fail to happen, as a result of the way that human beings relate to one another [35] therefore, understanding social capital puts a focus on people and how they interact with each other.

\section{Methods}

This study used a qualitative approach that included 17 semi-structured interviews and several weeks of observation of staff behaviour and actions, to enhance understanding about social capital formation, maintenance, and influence of that behaviour and action on organisational climate for innovativeness. Interviews consisted of semi-structured open questions around themes, such as innovative processes, social networks, team spirit, communication, politics, education and satisfaction. The qualitative data was analysed with coding assistance from QSR NViVO 9 software, before comparative analysis was used to develop themes.

\section{Results and Analysis}

This study found that the nature and strength of interconnections between people in the operating suite has bearing on the climate for change and innovativeness (aspects of openness to doing things differently, accepting/embracing ideas from outside, acceptance of risk taking, fostering team spirit, considering the effects of internal politics, levels of staff motivation, and levels of commitment to organisational goals).

We first establish understanding of social capital in an operating suite environment. This provides managers with an insight into how fostering social capital may influence a climate of change and innovativeness in their work place. According to interviewees, social networks are structured predominantly in professional segregations, as one nurse manager shared:

"You've got the surgeons, you've got anaesthetics staff as

in anaesthetists

which sometimes 


\begin{abstract}
associate with the
anaesthetic nurses,

then you have got

the anaesthetic

nurses and recovery

nurses, then you

have got the scrub

scout nurses, and

then you've got the

OAs."
\end{abstract}

This segregation is also noted in the literature, which suggests that reinforcement of relationships is provided by homogeneity such as within a profession or clinical specialty. [4547] Social networks that are based on professional boundaries vary in size in accordance with the representation of each group in an operating theatre suite. For example, the scrub and scout nurses have the greatest presence and therefore have the largest social network, which consists of subgroups, as do the smaller profession-based social networks. One nurse's comments support the findings of the literature that further social network segregation also occurs according to life stage and lifestyle. $[48,49]$

$$
\begin{aligned}
& \text { "The young people } \\
& \text { have a very strong } \\
& \text { social group, we } \\
& \text { have another older } \\
& \text { group, ... the ones in } \\
& \text { the middle are the } \\
& \text { ones with kids, and } \\
& \text { then you have the } \\
& \text { specialty groups } \\
& \text { within the unit, they } \\
& \text { form around the } \\
& \text { specialty, so the } \\
& \text { people who work in } \\
& \text { cardiac will do things }
\end{aligned}
$$

as a group, um, the

people who work

with ENT."

The informal socialising ties of this deeper level of segregation are described in previous research [48] as the most liquid form of social capital. Relationships move from being solely instrumental and work-related to more expressive and affective elements. This change increases the level of trust between members through greater time, opportunity and motivation to strengthen and broaden their relationship. $[50,51]$ These comments describe strong ties and support the literature that the strength of a tie is determined by a combination of the amount of time invested, and the level of emotional intensity, intimacy and reciprocity. [52,53]

It is our premise that strong ties are found to provide a sense of unity, support and a platform of values and beliefs, preparing for innovativeness. Whilst shared values and beliefs can provoke internal politics if they are not shared by all, strong ties between staff will provide a level of trust to present and embrace new ideas and provide for a level of motivation and shared risks.

Strong network ties are a basis for building social capital. However, strong network ties can also be difficult to manage. One NUM in the small operating theatre suite described how the social capital of some of the subgroups with close ties can become limiting to the climate for change and innovativeness:

$$
\begin{aligned}
& \text { "There [is] a bit of a } \\
& \text { gang mentality, one } \\
& \text { staff member would } \\
& \text { ark up about a }
\end{aligned}
$$




\author{
certain issue and \\ they would all get on \\ board."
}

This comment is in accordance with findings of the strong ties literature that ties can sometimes be too strong [48] and result in the negative aspects of the dark side of social capital. In one of the operating theatre suites it was observed how the staff perceived the unit as extremely specialised and that no experience or ideas from other operating theatre suite or acute health service could be relevant to their particular setting. This demonstrates an instance groupthink of how 'the way we do things here' is the only accepted way and provides a barrier to openness and innovativeness.

A nurse educator acknowledges the existence of exclusiveness in operating theatre suites:

"Theatre is a hard

area to break into; I don't think that is just in theatre, I think that is in just about any specialist area."

The nurse educator suggests that the tight closure of the social networks in the operating theatre suite is related to the highly specialised nature of the environment. Excessive closure, the dark side of social capital, promotes exclusiveness, leading to negative impacts such as collective blindness, groupthink, and limitations on the group's openness to alternative practices and outside information [43] and is detrimental to a climate for change and innovativeness. This finding is an advance to the organisational social capital literature and an important consideration in promoting a climate for change and innovativeness. In addition to strong ties, there is also evidence of some weaker ties in the three operating theatre suites investigated.

A NUM demonstrated bridging social capital through her involvement in different committees:

$$
\begin{aligned}
& \text { "Because of all the } \\
& \text { committees that I sit } \\
& \text { on, um, I am in touch } \\
& \text { with biomedical } \\
& \text { engineers, physicists, } \\
& \text { um, accreditation } \\
& \text { people, I mean my } \\
& \text { colleagues would } \\
& \text { have that access, but } \\
& \text { I have probably got } \\
& \text { more of a } \\
& \text { relationship because } \\
& \text { I am dealing with } \\
& \text { them so much." }
\end{aligned}
$$

This comment demonstrates the NUMs' access to external professionals that represent great power and authoritative networks, and although the NUM acknowledges that her colleagues would also have that access, she indicates that her investment in and access to social capital with external professionals may be stronger than her colleagues through more frequent interaction. This is consistent with Bourdieu's $[34,47,54,55]$ view that investment in social connections reinforces and maintains social capital for future use, such as influencing a climate for change and innovativeness.

A diverse range of information and ideas provides opportunity to create unique combinations and innovative solutions to operating theatre suite problems. In addition 
to internal bridges within the teams, bridges to networks outside of the operating theatre suite and outside of the organisation provide opportunity for combining existing knowledge with new knowledge and to promote innovativeness. A healthy climate for change and innovativeness relies on a level of openness between internal networks to allow cooperation and knowledge transfer to generate and utilise innovativeness. Bridges between internal networks are important to support a climate for change and innovativeness. This finding of this study is not apparent in the literature and therefore represents an advance on understanding bridging capital.

\section{Discussion}

Bridging ties are found to provide individual benefit through membership, satisfaction and support, and collective benefits of openness, collaboration, resourcefulness, and organisational commitment. Therefore, an understanding of social capital within organisational units may assist managers to facilitate a climate for change and innovativeness by promoting particular types of connections between team members. Some of this is already attempted, especially in the large and small operating suite. It was observed that the large and small operating theatre suites provide a greater number of opportunities for staff to participate in meetings and education sessions. However, in the medium operating theatre suite, meetings are scheduled less frequently, on fixed days, during an afternoon theatre session, and regularly cancelled, which places greater reliance on social capital and informal knowledge sharing. Therefore, in that particular operating suite, managers should attend to creating bridging ties and the opportunities that present for improving the climate for change and innovativeness by scheduling gatherings more thoughtfully.

The literature, [56-58] regards a high level of closure and tie strength in professional subgroups, and a large number of bridging ties with other networks as a dual network structure. Bhandari and Yasunobu [59] suggests that a dual network structure can positively influence social capital. The benefit of a dual network structure is described in the literature [56] as the coexistence of bridges for structural holes to provide access to diverse resources, in addition to the network cohesion that is required to build trust, accomplish common goals and consequently promote innovativeness. Therefore, it would be beneficial for managers of operating theatre suites to stimulate internal and external bridging ties, in addition to social cohesion to build strength of ties whilst promoting openness to enhance a climate for change and innovativeness.

In terms of social capital, the concept of "Internal politics" provides another layer of commonality that can lead to exclusivity through alignment of different values and beliefs. Participants in this study discussed internal politics in terms of influences of power held by certain professional and nonprofessional sub-groups e.g. doctors, older workers, gender etc. The power of the subgroups was described as somewhat exclusive and influencing the behaviour of non-group members. However, some sub-groups have formed around special interests outside the workplace, such as quilting, and are found to span boundaries of clinical specialties and life stages, thus providing strong bridging ties 
between sub-groups, without density and homogeneity.

In this study, internal politics in the operating theatre suite is found to be indicative of the presence of strong social capital in clinical specialties and life stage groups, but not necessarily found to be a factor in special interest groups. Therefore, internal politics are less present in strong bridging ties which are developed without density; a lack of density reduces exclusivity and enhances openness to outside ideas and resources. $[60,61]$

The chosen organisational internal structures for allocation of members are found in this study to influence the type of social capital connections between organisational members. For instance, the medium operating theatre suite organisational structures allow specialty sub-groups to retain their members by maintaining clinical specialty allocation of individual staff members, whereas the large and small operating theatre suites rotate staff through clinical specialties to promote multiskilling.

In the small and large operating theatre suites, rotation between specialties may dilute the paradigms of individual specialties, providing opportunity for a shared set of values to develop broadly in the operating theatre suite. However, rotation through specialties also facilitates a reduction of frequent interaction, particularly in the greater pool of the large operating theatre suite, which may reduce structural foundations for bridging social capital to develop among staff.

On the other hand, rotation in the small operating theatre suite may provide enough distance between organisational members to negate density and social capital becoming too strong. Therefore, organisational structural choices need to consider the size of the pool of organisational members and address the factors of frequency of interaction, density and bridging opportunities. Structures and policies can promote optimal tie strength and value sharing to achieve a balance between individual and organisational benefits of social capital in an operating theatre suite. This may be achieved in practice through frequent meetings and opportunities for social interaction in combination with staff rotation and multidisciplinary committees to facilitate diverse work-based networks and bridges between diverse groups. However, other organisational contextual factors such as size should also be considered.

Different policies of staff allocation in combination with differently sized operating theatre suites are evidenced to have different influences on social capital. Contextual characteristics may promote density with some small groups and reduce frequency of interaction with others, and this is demonstrated to reduce openness, promote exclusivity and provoke internal politics. These factors in turn affect the climate for change and innovativeness in an operating theatre suite; however, these characteristics can be managed in differently sized operating theatre suites through facilitation of social capital through practices such as staff allocation policies, formal meetings, informal social meetings, and promoting openness. This study has found that managers of acute health services may use structures and policies to develop social capital, both formally and informally, to facilitate a climate for change innovativeness.

\section{Conclusion}


Understanding social capital in an organisational context provides a peoplefocused perspective to managing a climate for change and innovativeness. Such a perspective is relevant in acute health services as social structures in this context have previously proved resistant to organisational change initiatives. [62]

It is apparent that social capital may provide a new perspective to address certain weaknesses of a climate for change and innovativeness. For instance, openness, internal politics and organisational commitment are manageable through policies that facilitate social capital. Although related, organisational climate and social capital are found to be neither dependent on nor mutually exclusive to each other and must be assessed in context. These results are an advance on existing literature and provide opportunity to start the conversation and design specifically focused initiatives to facilitate and manage social capital and climate for change and innovativeness in an acute health service context.

The contribution of this study to theory and practice is the explicit attempt to link social capital to a climate for change innovativeness, adding social capital as a relevant construct of organisational context. This study has highlighted the complexity of these concepts. Managing social capital can offer a peoplefocused perspective through which to design and implement change and enhance a climate for change innovativeness. 


\section{References}

1. Duckett SJ, Wilcox S. The Australian Health Care System. Fourth ed. Melbourne: Oxford University Press; 2011.

2. Johar M, Savage E, Stavrunova O, Jones G, Keane M. Geographic Differences in Hospital Waiting Times. Economic Record. 2012;88(281):165-81.

3. Pandit JJ, Pandit M, Reynard JM. Understanding waiting lists as the matching of surgical capacity to demand: are we wasting enough surgical time? Anaesthesia. 2010;65(6):625-40.

4. Van Lerberghe $W$. The world health report 2008: primary health care: now more than ever: World Health Organization 2008.

5. Walters JL, Mackintosh SF, Sheppard L. Snakes and ladders: the barriers and facilitators of elective hip-and kneereplacement surgery in Australian public hospitals. Australian Health Review. 2013

6. Glouberman S, Mintzberg H. Managing the care of health and the cure of disease--part I: Differentiation. Health Care Management Review. 2001;26(1):56

8. Kocher R, Sahni NR. Physicians versus hospitals as leaders of accountable care organizations. New England Journal of Medicine. 2010;363(27):2579-82

9. Curtis AJ, Russell $\mathrm{COH}$, Stoelwinder JU, McNeil JJ. Waiting lists and elective surgery: ordering the queue. Medical Journal of Australia. 2010;192(4):217-20.

10. Bentley C, Browman G, Poole B. Conceptual and practical challenges for implementing the communities of practice model on a national scale-a Canadian cancer control initiative. BMC Health Services Research. 2010;10(1):3..

11.'Harty C. Implementing innovation: designers, users and actor-networks. Technology Analysis \& Strategic Management. 2010;22(3):297-315.

12. Griffith JF, Weisberg SB. Challenges in implementing new technology for beach water quality monitoring: lessons from a California demonstration project. Marine Technology Society Journal. 2011;45(2):65-73.

13. Undre S, Sevdalis N, Healey AN, Darzi SA, Vincent CA. Teamwork in the operating theatre: cohesion or confusion? Journal of Evaluation in Clinical Practice. 2006;12(2):182-9
7. Garside P. Are we suffering from change fatigue? Quality and Safety in Health Care. 2004;13(2):89-90.

15. Oberlander J. Long time coming: why health reform finally passed. Health Affairs. 2010;29(6):1112-6.

16. Werner RM, McNutt R. A new strategy to improve quality. JAMA: the journal of the American Medical Association. 2009;301(13):1375-7.

17. Scott IA. Health care workforce crisis in Australia: too few or too disabled? Medical Journal of Australia. 2009;190(12):689.

18. Hall J. Health care reform in Australia: advancing or side stepping? Health Economics. 2010;19(11):1259-63.

19. Cunningham PA. The future of community-centred health services in Australia "an alternative view. Australian Health Review. 2012;36(2):121-4.

20. Denis J-L, Forest P-G. Real reform begins within: an organizational approach to health care reform. Journal of Health Politics, Policy and Law. 2012;37(4):633-45.

14. Brunero S, Lamont S. The process, logistics and challenges of implementing clinical supervision in a generalist tertiary referral hospital. Scandinavian journal of caring sciences. 2012;26(1):186-93

21. Hall J. Australian health care reform: giant leap or small step? Journal of health services research \& policy. 2010;15(4):193-4.

22. van Rossum L, Aij KH, Simons FE, van der Eng N, ten Have WD. Lean healthcare from a change management perspective: The role of leadership and workforce flexibility in an operating theatre. Journal of health organization and management. 2016;30(3):475-93

23. Kaplan GS, Patterson SH, Ching JM, Blackmore CC. Why Lean doesn't work for everyone. BMJ quality \& safety. 2014:bmjqs2014-003248.

24. de Souza LB, Pidd M. Exploring the barriers to lean health care implementation. Public Money \& Management. 2011;31(1):59-66.

25. Black H. Working together: Managing social capital to facilitate an organisational climate for innovativeness in an acute health service context. Gold Coast, Australia: Griffith University; 2015. 
26. Granovetter MS. Economic action and social structure: The problem of embeddedness. American Journal of Sociology. 1985;91:481-510.

27. Perry-Smith JE, Shalley CE. The Social Side of Creativity: A Static and Dynamic Social Network Perspective. Academy of Management Review. 2003;28:89-106

28. Coleman J. Social capital in the creation of human capital. American Journal of Sociology. 1988(94):95-120.

29. Krackhardt D. The Strength of Strong Ties: The importance of Philos in Oganizations. In: Nohria N, Eccles RG, editors. Networks and Organizations: Structure, Form and Action. Boston: Harvard Business School Press; 1992.

30. Reagans R, Zuckerman E. Networks, diversity, and productivity: the social capital of corporate R \& D teams. Organizational Science. 2001;12:502-17.

31. Smith K, Collins C, Clark K. Existing knowledge, knowledge creation capability, and the rate of new product introduction in high-technology firms. Academy of Management Journal. 2005;48:346-57.

32. Zheng W. A Social Capital Perspective of Innovation from Individuals to Nations: Where is Empirical Literature Directing Us? International Journal of Management Reviews. 2010;12(2):151.

33. Burt RS. The contingent value of social capital. Administrative Science Quarterly. 1997;42:339-65.

34. Bourdieu P. The forms of capital. In: Richardson J, editor. Handbook of theory and research for sociology. Cambridge: Harvard University Press; 1986.

35. Cohen D, Prusak L. In Good Company: How social capital makes organizations work. Boston: Harvard Business School Press; 2001.

36. Fukuyama F. Trust: the Social Virtues and the Creation of Prosperity. New York: Free Press; 1995.

37. Hanifan LJ. The Rural School Community Center. Annals of the American Academy of Political and Social Science. 1916;67:130-8.

38. Putnam RD. The prospreous community: Social capital and public life. Am Prospect. 1993;13(35):42.

39. Putnam RD. Social Capital: Measurement and Consequences. Canadian Journal of Policy Research. 2001;2(1):41-51.

40. Yang K. Individual Social Capital and It's measurement in Social Surveys. Survey Research Methods. 2007;1(1):19-27.

41. Evans WR, Davis WD. High-performance work systems and organizational performance: The mediating role of internal social structure. Journal of management. 2005;31(5):758-75.
42. Collins CJ, Clark KD. Strategic human resource practices, top management team social networks, and firm performance: The role of human resource practices in creating organizational competitive advantage. Academy of management Journal. 2003;46(6):740-51

43. Nahapiet J, Ghoshal S. Social capital, intellectual capital, and the organizational advantage. Academy of Management Review. 1998;23:242-66.

44. Hansen MT, Mores ML, Lovas B. Knowledge sharing in organizations:multiple networks, multiple phases. Academy of Management Journal. 2005;48:776-93.

45. Lin N. Social Capital: a theory of social structure and action. Cambridge: Cambridge University Press; 2001.

46. Schuller T, Baron S, Field J. Social Capital: A review and critique. In: Baron S, Field J, Schuller T, editors. Social Capital. Oxford: Oxford University Press; 2000.

47. Woolcock M. The Place of Social Capital in Understanding Social and Economic Outcomes. Isuma: Canadian Journal of Policy Research. 2001;2(1):1-17.

48. Oh H, Chung M-H, Labianca G. Group Social Capital and Group Effectiveness: The Role of Informal Socializing Ties. Academy of Management Journal. 2004;47(6):860-75.

49. Lau DC, Murnighan JK. Interactions within Groups and Subgroups: The Effects of Demographic Faultlines. Academy of Management Journal. 2005;48(4):645-59.

50. Fischer G, Scharff E, Ye Y. Fostering Social Creativity by increasing social capital. In: Huysman M, Wulf V, editors. Social Capital and Information Technology. Massachusetts Massachusetts Institute of Technology; 2004.

51. Labianca G, Umphress EE, Kaufmann J, editors. A preliminary test of the negative asymmetry hypothesis in workplace social networks. 60th Annual Meeting of the Academy of Management, Toronto; 2000.

52. Granovetter MS. The strength of weak ties. American Journal of Sociology. 1973;78:1360-80.

53. Meckler M. Links and Synchs: Organizations and organizational culture from a network point of view. In Ashkanasy NM, Wilson T, Peterson MF, editors. The Handbook of Organizational Culture and Climate. Thousand Oaks: Sage; 2011. p. 441-62.

54. Baum F, Ziersch A. Social Capital. Journal Epidemiology and Community Health. 2003;57(5):320-3.

55. Woolcock M. Social capital and Economic Development toward a theoretical synthesis and policy framework. Theory and Society. 1998;27(2):151-208.

56. Capaldo A. Network structure and innovation: the leveraging of a dual network as a distinctive relational capability. Strategic Management Journal. 2007;28:585-608. 
57. Fleming L, Marx M. Managing creativity in small worlds. California Management Review. 2006;48(4):6-27.

58. Uzzi B, Spiro J. Collaboration and Creativity: the small world problem. American Journal of Sociology. 2005;111:447-504.

59. Bhandari H, Yasunobu K. What is Social Capital? A comprehensive review of the concept. Asian Journal of Social Science. 2009;37:480-510.
60. Hurley RF, Hult GTM. Innovation, Market Orientation, and Organizational Learning: An Integration and Empirical Examination. Journal of Marketing. 1998;62:42-54.

61. Scott SG, Bruce RA. Determinants of innovative behaviour: A path model of individual innovation in the workplace. Academy of Management Journal. 1994;37:580-607.

62. Braithwaite J, Westbrook MT, Hindle D, ledema RA, Black DA. Does restructuring hospitals result in greater efficiency? an empirical test using diachronic data. Health Services Management Research. 2006;19(1):1-12. 